\title{
Evaluasi Kekuatan Struktur Atas Pada Gedung Gas Negara Fakultas Teknik Unmer Madiun Akibat Kemiringan Bangunan
}

\author{
1) Wildan Muzakky, ${ }^{2)}$ Seno Aji, ${ }^{3)}$ Rendi Gusta Wibowo \\ 1) Mahasiswa Sarjana Program Teknik Sipil, Universitas Merdeka Madiun, Jl. Serayu No. 79 Madiun \\ E-mail:muzakkyw@gmail.com ${ }^{1)}$, \\ 3) 2) Dosen Teknik Sipil, Universitas Merdeka Madiun, Jl. Serayu No. 79 Madiun \\ E-mail:senoaji@unmer-madiun.ac.id,rendigusta@gmail.com
}

\begin{abstract}
In a building, the beams and roof frame rest on the upright standing columns of each column is a very important technical factor before the blocks and roof frame are installed. Although a column does not stand vertically, it is a serious problem that will occur in terms of construction, it should be avoided. If the angle value of deviation in the column is outside tolerance, causing difficulties in the installation of construction. The peak of the column that has shifted from its position resulted in a tilted roof frame. This measurement uses an upfront cutting method. While on the upfront cropping method use the center of the column as the target point. Thus this research has proven that the method of cutting the surface is not only more flexible, but also more useful to control the firmness of the column on building construction work. Evaluation of the strength of the upper structure of the building at the time of tilting that can be seen from the repetition of.
\end{abstract}

Keywords—: column firmness, upfront cropping, evaluation

\section{PENDAHULUAN}

Gedung Gas Negara terletak di Kota Madiun. Gedung ini telah terbangun dan tampak ada beberapa kolom terlihat sedikit agak miring. Kemiringan bangunan dapat dilihat dan diukur menggunakan metode pengukuran dengan alat teodolit. Hal ini dilakukan agar diperoleh hasil data yang akurat. Berdasarkan hal tersebut, maka dilakukan sebuah studi yang berjudul "Evaluasi Kekuatan Struktur Atas Pada Gedung Gas Negara Fakultas Teknik Unmer Madiun Akibat Kemiringan Bangunan.

Cara yang umum yang dipergunakan untuk melakukan pengukuran ketegakan kolom yakni dengan cara pemotongan kemuka pada as kolom atas dan as kolom bawah. Cara tersebut relatif mudah dilaksanakan apabila jarak antar kolom relatif lebar, dan kondisi lapangan cukup bersih (tanpa halangan berarti). Tujuan evaluasi ini adalah untuk mendapatkan data jarak geser kemiringan bangunan serta yang kedua adalah untuk mengetahui evaluasi kekuatan struktur atas bangunan pada saat keadaan miring.

\subsection{Tinjauan Pustaka}

\section{METODE PENELITIAN}

Pada penelitian yang dilakukan oleh oleh Claduia Marina P, Jorry D, Pangouw, Ronny E.Pandaleka (2016) dalam "Perencanaan Struktur Gedung Hotel Jalan Martadinata Manado".Dinding geser adalah slab beton bertulang yang dipasang dalam posisi vertikal pada sisi gedung tertentu yang berfungsi menambah kekakuan struktur dan menyerap gaya geser yang besar seiring dengan semakin tingginya struktur. Fungsi dinding geser dalam suatu struktur bertingkat juga penting untuk menopang lantai pada struktur dan memastikannya tidak runtuh ketika terjadi gaya lateral akibat gempa.

Sedang pada penelitian yang dilakukan oleh Arikris Siboro, M. Yusuf dan Aryanto (2017) dengan judul "Perhitungan Struktur Beton Bertulang Gedung Kantor Tujuh Lantai di Pontianak" diketahui bahwa perencanaan struktur sendiri bertujuan guna menghasilkan suatu struktur yang stabil, cukup kuat, mampu layan, awet dan juga memenuhi tujuan lain seperti ekonomis dan juga kemudahan dalam suatu pelaksanaan. Suatu struktur dapat dikatakan stabil apabila ia tidak mudah terguling, miring atau tergeser selama umur bangunan yang telah direncanakan. Suatu strutur dapat dikatan cukup kuat dan mampu layan apabila kemungkinan terjadinya kegagalan struktur dan kehilangan kemampuan layan selama masa hidup yang direncanakan adalah kecil dan juga dalam batas yang dapat diterima. Dan suatu struktur dapat dikatakan awet apabila struktur tersebut dapat menerima keausan dan kerusakan yang diharapkan terjadi selama umur bangunan yang telah direncanakan tanpa sebuah pemeliharaan yang berlebihan. 
Website : $\underline{\text { http://pilar.unmermadiun.ac.id/index.php/pilarteknologi }}$

\subsection{Dasar Teori}

A. Sistem Kerja Beban

Beban Mati

Menurut Peraturan Pembebanan Indonesia Untuk Bangunan Gedung (PPIUG 1983) Beban mati merupakan suatu berat dari semua bagian bangunan gedung yang bersifat tetap,dan termasuk segala unsur tambahan, penyelesain - penyelesaian, mesin - mesin serta peralatan tetap yang merupakan bagian yang tak terpisah dari gedung tersebut.

Beban Hidup

Menurut Peraturan Pembebanan Indonesia Untuk Bangunan Gedung (PPIUG 1983) Beban Mati merupakan semua beban yang terjadi akibat penghuninya atau pengguna suatu gedung tersebut. Dan juga termasuk beban - beban yang berasal dari barang - barang yang dapat berpindah. Beban hidup tidak termasuk beban angin, beban gempa dan beban khusus.

Beban Angin

Menurut Peraturan Pembebanan Indonesia Untuk Bangunan Gedung (PPIUG 1983) Beban Angin adalah semua beban yang bekerja pada gedung atau bagian gedung yang disebabkan oleh selisih dalam keadaan tekanan udara. Tekanan tiup harus diambil minimum $25 \mathrm{~kg} / \mathrm{m} 2$, kecuali untuk daerah dilaut dan ditepi laut sampai sejauh $5 \mathrm{~km}$ dari tepi pantai. Pada daerah tersebut tekanan hisap diambil minimum $40 \mathrm{~kg} / \mathrm{m} 2$

\section{Beban Gempa}

Menurut Peraturan Tata Cara Ketahanan Gempa Untu Struktur Bangunan Gedung Dan Non Gedung, SNI 03- 1726-2012. Beban gempa adalah semua beban statik ekivalen yang bekerja pada gedung atau bagian gedung yang menirukan pengaruh dari gerakan tanah akibat gempa.

B. Ketetntuan Mengenai Kekuatan Kemampuan Layan.

Menurut SNI 03 - 2847 - 2002 pasal 11.1 Stuktur dan segala komponen struktur harus direncanakan hingga semua penampang mempunyai kuat rencana minimum sama dengan kuat perlu, yang dihitung berdasarkan kombinasi beban dan gaya terfaktor yang sesuai dengan ketentuan tatacara ini.

C. Kuat Perlu

Menurut Tata Cara Perhitungan Struktur Beton Untuk Bangunan Gedung SNI 03-2847-2002 pasal 11.2. Kuat perlu pada suatu komponen struktur merupakan kakuatan yang terjadi akibat dari beban dikalikan dengan faktor beban. berikut faktor pembebanan kuat perlu (U)

$\mathrm{D} \quad=1,4 \mathrm{D}$

$\mathrm{D}, \mathrm{L} \quad=1,2 \mathrm{D}+1,6 \mathrm{~L}$

$\mathrm{D}, \mathrm{L}, \mathrm{E}=1,2 \mathrm{D}+1 \mathrm{~L} \pm 1 \mathrm{Ex} \pm 0,3 \mathrm{Ey}$

$\mathrm{D}, \mathrm{L}, \mathrm{E}=1,2 \mathrm{D}+1 \mathrm{~L} \pm 0,3 \mathrm{Ex} \pm 1 \mathrm{Ey}$

Berdasarkan SNI 03-1726-2013 pasal 7.4.2 bahwa penggunaan kombinasi beban gempa harus ditentukan dengan persamaan sebagai berikut:

$\mathrm{E} \quad=\mathrm{Eh}+\mathrm{Ev}$

$\mathrm{E} \quad=$ Pengaruh beban gempa

Eh $\quad=$ Pengaruh beban gempa horizontal

$\mathrm{Ev} \quad=$ Pengaruh beban gempa vertikal

Eh $\quad=\rho$. QE

$\rho \quad=$ Faktor redudansi

$\mathrm{QE} \quad=$ Pengaruh gaya gempa horizontal dari $\mathrm{V}$ atau $\mathrm{Fp}$

Ev $\quad=0,2$. SDS.D

$\mathrm{D} \quad=$ Pengaruh beban mati

SDS = Parameter respon spektral percepatan desain pada perioda pendek

D. Kuat rencana

Suatu komponen struktur menurut SNI 03-2847-2002 pasal 11.3 (1) tentang Tata Cara Perhitungan Struktur Beton Bertulang Untuk Bangunan Gedung, merupakan hasil kali dari kuat nominal dengan suatu faktor reduksi kekuatan (Ø). 
Website : $\underline{\text { http://pilar.unmermadiun.ac.id/index.php/pilarteknologi }}$

\section{E. Balok}

Balok merupakan bagian dari elemen struktur yang digunakan sebagai dudukan pelat lantai dan ikatan pada kolom yang berfungsi menyalurkan beban mati maupun beban hidup dari pelat lantai ke kolom, yang menerima beban tarik dan tekan karena adanya gaya lentur ataupun gaya lateral.

Prosedur dalam merencanakan balok lentur sesuai dengan rumus sebagai berikut :

Menentukan asumsi dimensi rencana tinggi balok (h).

Menentukan asumsi lebar flens efektif (b), dengan persaman :

"b=" "2" /"3" " .h"

Menetapkan tinggi efektif balok dengan persamaan :"d" _" efektif" " = h - p - 1/2" ."Ø tul utama"

Menghitung momen rencana ( $\mathrm{Mu}$ ) akibat gaya-gaya yang bekerja.

Mu diperoleh dari hasil analisis SAP 2000 yaitu Mu sebesar pada tumpuan dan lapangan.

Menghitung momen tahanan ( MR ), dengan anggapan bahwa seluruh daerah flens efektif tekan.

Mencari tulangan balok dengan menerapkan persamaan-persamaan berikut ini :

" $\rho$ min = " "1,4" /"fy"

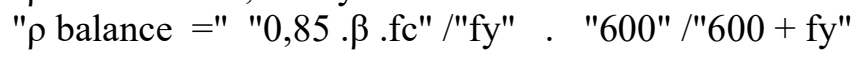

$" \rho \max =0,75 . \rho$ balance "

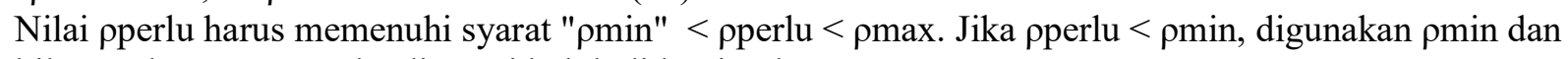
bila $\rho$ perlu $>\rho$ max maka dimensi balok didesain ulang.

"Rn = " "Mult" /("ф.b." "d"^"2" " " )

"m = " "fy" /"0,85 .fc "

" $\rho$ perlu = " "1" /"m" ("1 - " $\sqrt{ }(" 1$ - " "2 .m .Rn" /"fy" ))

As perlu $\quad=\rho \cdot \mathrm{b} \cdot \mathrm{d}$

Kontrol tulangan tarik minimum, dengan persamaan : " $\rho=$ " "As pakai" /"b .d" " $\geqslant \rho \min "$

Menghitung gaya geser maksimum $(\mathrm{Vu})$

$\mathrm{Vu}$ diperoleh dari hasil analisis SAP 2000 yaitu Vu sebesar pada tumpuan.

Menghitung gaya geser nominal (Vn), dengan menggunakan persamaan yang pada mengacu SNI 032847-2002 pasal 11 (11.3)

"Vn = " "Vu" /" $\phi "$

Dimana, $\phi=0,75$

Hitung gaya geser yang mampu diterima oleh beton $(\mathrm{Vc})$

"Vc = " "1" /"6" $\sqrt{ }(" \mathrm{fc} ")$ " .b .d"

Analisa apakah balok perlu tulangan sengkang atau tidak.

Jika $\mathrm{Vu}>\phi . \mathrm{Vc}$, dan 0,5. $\phi \neg$. Vc, maka diperlu tulangan geser

Hitung gaya geser yang mampu diterima oleh sengkang (Vs)

"Vs $=\mathrm{Vn} . \mathrm{Vc} "$

Hitung jarak tulangan dan kebutuhan sengkang

"Av = n " "1" /"4" " . . . "d" ^"2"

"Sperlu = " "Av .fy .d" /"Vs"

"Smax = " "d" /"2"

Kontrol kebutuhan sengkang dengan persamaan :

"1" /"3" $\sqrt{ }($ "fc") ) ".b .d > Vs"

F. Kolom

Kolom adalah batang tekan vertikal dari rangka struktur bangunan yang bertugas memikul beban aksial dan tekan vertikal dari balok. Kolom berfungsi meneruskan beban mati maupun beban hidup dari balok ke tanah melalui pondasi.

Berdasarkan SNI 03-2847-2002 kolom merupakan komponen struktur dengan rasio tinggi terhadap dimensi lateral terkecil melebihi 3 yang digunakan terutama untuk mendukung beban aksial tekan.

Prosedur dalam merencanakan balok lentur sesuai dengan rumus sebagai berikut :

Menentukan dimensi rencana dan perhitungan pembebanan pada kolom.

Menghitung gaya aksial ( $\mathrm{Pu}$ ) akibat gaya-gaya yang bekerja.

Pu diperoleh dari hasil analisis SAP 2000 yaitu Pu sebesar pada tumpuan.

Menghitung momen rencana ( $\mathrm{Mu}$ ) akibat gaya-gaya yang bekerja. 


\section{Website : http://pilar.unmermadiun.ac.id/index.php/pilarteknologi}

Mu diperoleh dari hasil analisis SAP 2000 yaitu Mu sebesar pada tumpuan dan lapangan.

Menentukan kategori kolom

" " "K lu" /"r" "<34 - 12 " ("M1" /"M2" ), maka termasuk jenis kolom pendek

" " "K lu" /"r" "> 34 - 12 " ("M1" /"M2" ), maka termasuk jenis kolom panjang

Perhitungan eksentrisitas kolom $(\mathrm{e}>\mathrm{emin}$, maka digunakan $\mathrm{e})$

"e = " "Mult" /"Pult" " "

emin $=15+0,003$.h

e $>$ emin, maka digunakan e

Menentukan tinggi efektif kolom

d' $\quad=p+$ Øsengkang $+1 / 2$ Øtulangan utama

$\mathrm{d} \quad=\mathrm{h}-\mathrm{d}$ '

Memeriksa Pu terhadap beban pada keadaan seimbang $\phi$ Pnb

"Cb = " "600" /"600 + fy" ".d "

"Ab $=\beta 1 . \mathrm{Cb} "$

Berdasarkan SNI 03-2847-2002, pasal 12.9(1), pembatasan luas tulangan longitudinal untuk komponen struktur tekan non-komposit tidak boleh kurang dari 0,01 atau lebih besar dari 0,08 kali luas bruto penampang kolom Ag.

"Ab = " $\rho "$.Ag "

"عs' = " 0,003" ." (("Cb-d"'))/"Cb" " "

"fs' = Es .es'"

fs' > fy, maka selanjutnya di dalam perhitungan digunakan fs' $=$ fy

Analisa kehancuran kolom

$" \varphi$ Pnb $=\phi .(0,85$.fc.Ab.b $)+($ As'.fs-As.fy $) "$

$\phi . P n b>\mathrm{Pu}$, maka beeton mengalami hancur tarik

$\phi . \mathrm{Pnb}<\mathrm{Pu}$, maka beeton mengalami hancur tekan

Dimana, $\phi=0,65$

Cek kekuatan penampang

" $\rho$ aktual = " "As" /"b.d"

"m = " "fy" /"0,85.fc"

Kontrol kekuatan penampang kolom persegi

Kolom dengan kehancuran tarik

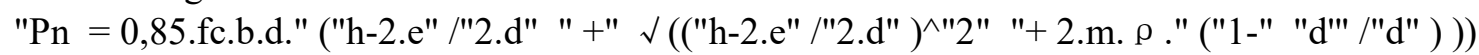

Kolom dengan kehancuran tekan

"Pn = " ("A" "s" ^"'"' ".fy" )/("e" /(("d-d"' ) ) " + 0,5" ) "+" "b.h.fc" /("3.he" /(("d" ^"2" ) ) " + 1,18" )

Syarat kolom aman apabila : $\phi . \mathrm{Pn}>\mathrm{Pu}$

Menghitung gaya aksial ( $\mathrm{Vu}$ ) akibat gaya-gaya yang bekerja.

$\mathrm{Vu}$ diperoleh dari hasil analisis SAP 2000 yaitu Vu sebesar pada tumpuan.

Menghitung luas kotor penampang Ag

$\mathrm{Ag}=\mathrm{b} . \mathrm{h}$

Hitung gaya geser yang mampu dipikul oleh beton $(\mathrm{Vc})$

"Vc = " ("1 +" "Nu" /"14 .Ag" ) "." "1" /"6" V ("fc" ) " .b .d"

Hitung gaya geser yang mampu diterima oleh sengkang (Vs)

$\mathrm{Vs} \quad=\mathrm{Vn}-\mathrm{Vc}$

Menghitung gaya geser nominal (Vn), dengan menggunakan persamaan yang pada mengacu SNI 03-

2847-2002 pasal $11(11.3)$

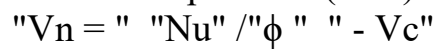

Dimana, $\phi=0,75$

Hitung jarak tulangan dan kebutuhan sengkang

"Av = n " "1" /"4" " . . . "d" ^"2"

"Sperlu = " "Av .fy .d" /"Vs"

"Smax = " "d" /"2" 
Pembebanan Pelat

Tebal plat

Beban Mati yang bekerja

Beban hidup yang bekerja

Beban ultimate

\section{HASIL DAN PEMBAHASAN}

Mtx $=-0,001 \cdot \mathrm{W}_{\text {ult. }} \mathrm{Lx}^{2} \cdot \mathrm{Ctx}$

Mtx $=-0,001.848,8 \cdot(3)^{2} .76$

$$
=-258,04 \mathrm{~kg} \cdot \mathrm{m}
$$

Dipakai tulangan Ø10-125 (As pasang $\left.=628 \mathrm{~mm}^{2}\right)$

Rekapitulasi Penulangan Pelat Lantai

\begin{tabular}{|c|c|c|c|c|}
\hline \multirow{2}{*}{$\begin{array}{c}\text { Tipe } \\
\text { Pelat }\end{array}$} & \multicolumn{2}{|c|}{ Lx } & \multicolumn{2}{c|}{ Ly } \\
\cline { 2 - 5 } & Tumpuan & Lapangan & Tumpuan & Lapangan \\
\hline A & $\varnothing 10-125$ & $\varnothing 10-125$ & $\varnothing 10-125$ & $\varnothing 10-125$ \\
\hline B & $\varnothing 10-125$ & $\varnothing 10-125$ & $\varnothing 10-125$ & $\varnothing 10-125$ \\
\hline
\end{tabular}

\section{Perencanaan Struktur Balok}

Dari hasil analisis struktur diperoleh:

$\mathrm{Mu} \quad=-13.951,55 \mathrm{~kg} \cdot \mathrm{m}$

$\mathrm{Vu} \quad=-11.865,89 \mathrm{~kg}$

Dimensi yang dipakai :

$\mathrm{b} \quad=300 \mathrm{~mm}$

$\mathrm{h} \quad=700 \mathrm{~mm}$

Perhitungan Momen Kapasitas Balok

Tulangan tarik 5 D16 \& $3 \varnothing 12\left(\mathrm{As}=1.004,8 \mathrm{~mm}^{2}\right.$

$$
\mathrm{Mn}=\frac{\mathrm{Mu}}{\Theta^{6}} \frac{63330100}{0,8}=79162625 \mathrm{Nmm}
$$

$\mathrm{Mn}>\mathrm{Mu}$ Balok aman terhadap lentur.

Perhitungan Kapasitas Geser Balok Kuat Geser Beton

$$
\begin{aligned}
\mathrm{Vc} & =\frac{1}{6} \sqrt{\mathrm{fc}} \cdot \mathrm{b} \cdot \mathrm{d} \\
& =\frac{1}{6} \sqrt{20} \cdot 250 \cdot 459 \\
& =141 \cdot 311,679 \mathrm{~N}
\end{aligned}
$$

Kuat geser baja tulangan

$$
\begin{aligned}
& \text { Vs }=\frac{A v . f y . d}{V s} \\
& =\frac{100.240 .459}{20889,007}=-11.593,813 \mathrm{~mm} \\
& \mathrm{~S}_{\max }=\frac{\mathrm{d}}{2}=\frac{459}{2}=327 \mathrm{~mm} \\
& \text { Maka dipakai tulangan geser Ø8-150 mm. }
\end{aligned}
$$

\section{Perencanaan Struktur Kolom}

$\mathrm{Nu} \quad=-34.208,2 \mathrm{~kg}$

$\mathrm{Mu} \quad=1.080,83 \mathrm{~kg} \cdot \mathrm{m}$

$\mathrm{Vu} \quad=458,37 \mathrm{~N}$

Kuat geser Kolom

$$
\frac{\mathrm{K} l u}{\mathrm{r}}<34-12\left(\frac{\mathrm{M} 1}{\mathrm{M} 2}\right)
$$


$\frac{0,5 \cdot 4500}{0,3 \cdot 300}<34-12\left(\frac{29744700}{46347800}\right)$

$16,667<23,901$

Maka pengaruh kelangsingan dapat diabaikan.

Kuat geser Kolom dengan tulangan geser Ø8-150 dengan tulangan utama 4 D16 (As $\left.=803,84 \mathrm{~mm}^{2}\right)$

\section{KESIMPULAN DAN SARAN}

Dari evaluasi kekuatan struktur atas pada Gedung Gas Negara Fakultas Teknik Unmer Madiun akibat kemiringan bangunan, diperoleh hasil sebagai berikut :

1. Pada gambar perencanaan penulangan balok B1 $(30 \times 70)$ diperoleh tulangan tarik 7 D16, tulangan tekan 3 D16 pada tumpuan, tulangan pinggang 2 Ø 10, tulangan tarik 3 D16, tulangan tekan 7 D16 pada lapangan dengan tulangan geser Ø8-150. Setelah dilakukan analisis diperoleh nilai tulangan tarik 5 D16, tulangan tekan 3 D16 pada tumpuan dan tulangan tarik 5 D16, tulangan tekan 3 D16 pada lapangan dengan tulangan geser Ø 8-150. Maka perencanaan balok B1 tersebut aman.

2. Pada gambar perencanaan penulangan balok $\mathrm{B} 2(20 \times 30)$ diperoleh tulangan tarik 3 D12, tulangan tekan 3 D12 pada tumpuan dan tulangan tarik 3 D12, tulangan tekan 3 D12 pada lapangan dengan tulangan geser Ø8-150. Setelah dilakukan analisis diperoleh nilai tulangan tarik 6 D12, tulangan tekan 3 D12 pada tumpuan dan tulangan tarik 3 D12, tulangan tekan 3 D12 pada lapangan dengan tulangan geser Ø 8-150. Maka perencanaan balok B2 tersebut aman.

3. Pada gambar perencanaan penulangan balok B3 $(20 \times 40)$ diperoleh tulangan tarik 3 D12, tulangan tekan 3 D12 pada tumpuan, dan tulangan tarik 3 D12, tulangan tekan 3 D12 pada lapangan dengan tulangan geser Ø8-150. Setelah dilakukan analisis diperoleh nilai tulangan tarik 4 D12, tulangan tekan 2 D12 pada tumpuan dan tulangan tarik 3 D12, tulangan tekan 2 D12 pada lapangan dengan tulangan geser Ø8-150. Maka perencanaan balok B3 tersebut aman.

4. Pada gambar perencanaan penulangan pada kolom K1 $(30 \mathrm{~cm} \times 35 \mathrm{~cm})$ menggunakan tulangan utama 4 D16 + $6 \varnothing 12$ dan tulangan geser $\varnothing 8-150$, setelah dilakukan analisis diperoleh tulangan utama 4 D16 dan tulangan geser Ø8-150, maka perencanaan kolom K1 tersebut aman.

5. Pada gambar perencanaan penulangan pada kolom $\mathrm{K} 2(25 \mathrm{~cm} \times 25 \mathrm{~cm})$ menggunakan tulangan utama 10 Ø12, sesudah dilakukan analisis diperoleh tulangan utama $5 \varnothing 12$ dan tulangan geser Ø8150, maka perencanaan kolom K2 tersebut aman.

\section{UCAPAN TERIMA KASIH}

Ucapan trimakasih disampaikan kepada semua pihak yang telah memberikan bantuan dalam penulisan Evaluasi Kekuatan Struktur Atas Pada Gedung Gas Negara Fakultas Teknik Unmer Madiun Akibat Kemiringan Bangunan khususnya kepada Ti peneliti.

\section{DAFTAR PUSTAKA}

Abdul Khaliq (2015) Analisis Struktur Tangga Proyek Pembangunan RSUD Cideres Majalengka.Teknik Sipil Fakultas Teknik Universitas Majalengka.

Abdul Khaliq (2015) Analisis Struktur Tangga Proyek Pembangunan RSUD Cideres Majalengka.Teknik Sipil Fakultas Teknik Universitas Majalengka

Arikris Siboro,M.Yusuf,Aryanto (2017) "Perhitungan Struktur Beton Bertulang Gedung Kantor Tujuh Lantai di Pontianak"

Anonim. (1971) Peraturan Beton Bertulang Indonesia, PBBI 1971, Badan Standardisasi Nasional, Bandung.

Anonim. (1983) Peraturan Pembebanan Indonesia Untuk Gedung, PPIUG 1983, Badan Standardisasi Nasional, Bandung.

Anonim. (2002) Tata Cara Perhitungan Struktur Beton Untuk Bangunan Gedung, SNI 03-2847-2002, Badan Standardisasi Nasional, Bandung. 
Website : $\underline{\text { http://pilar.unmermadiun.ac.id/index.php/pilarteknologi }}$

Anonim. (2012) Tata Cara Perencanaan Ketahanan Gempa Untuk Struktur Bangunan Gedung Dan Non Gedung, SNI 03-1726-2012, Badan Standardisasi Nasional, Bandung..

Claudia Maria P, dkk. (2016) perencanaan Struktur Gedung Hotel Jalan Martadinata Manado, Jurusan Teknik Sipil Fakultas Teknik Universitas Samratulangi, Manado.

Ir.Rudy Gunawan.(1987) Tabel Profil Konstruksi Baja,

Yuda Putra Ichwandri (2014) Perencanaan Struktur Gedung Astrama Mahasiswa Universitas Sriwijaya Palembang Dengan Penahan Lateral Dnding Struktural. Fakultas Teknik Jurusan Teknik Sipil Universitas Sriwijaya, Sumatra Selatan. 